ఠ

Open Access Full Text Article

REVIEW

\title{
Anthropogenic climate change: how to understand the weak links between scientific evidence, public perception, and low-carbon practices
}

This article was published in the following Dove Press journal:

Energy and Emission Control Technologies

25 January 2016

Number of times this article has been viewed

\section{Anita Engels}

Centre for Globalisation and Governance, Hamburg University, Hamburg, Germany
Correspondence: Anita Engels

Centre for Globalisation and Governance, Hamburg University, Allende-Platz I, 20146 Hamburg, Germany

Tel +4940428383832

Fax +4940428386404

Email anita.engels@uni-hamburg.de

\begin{abstract}
This review article presents an overview of recent literature on: the scientific consensus about the attribution of climate change to anthropogenic sources; successes and failures to create a global policy regime to lower worldwide carbon emissions; recent developments in the public perception of climate change and associated risks; and the persistence of highly carbon-intensive practices in spite of scientific evidence on the attribution of climate change to anthropogenic causes. Holistic approaches to understanding patterns of consumption, focusing on ensembles of social practices, may explain this persistence, however, such approaches are still in their infancy with regard to developing proactive ideas for policies to promote low-carbon practices more effectively.
\end{abstract}

Keywords: climate science, climate policies, social practices, skepticism, low-carbon development

\section{Introduction}

One puzzle regarding anthropogenic climate change is the discrepancy between the scientific assessment of the ensuing risks, and the relative lack of societal response to these risks. The identification and assessment of risk has occurred in modern society mostly with reference to scientific research. Since the 1980s, scientific research has generated a consensus regarding anthropogenic climate change-drastic reductions in greenhouse gas (GHG) emissions in the decades to come, are required to limit future climate change. This recommendation has been consistent over the past 20 years, and the assessment reports produced in this period are the single most collaborative scientific endeavor in the history of science. ${ }^{1}$ Thousands of scientists have contributed to these assessments, and the resources of hundreds of research institutions worldwide have been invested in this endeavor. Assessment reports commonly known as IPCC (Intergovernmental Panel on Climate Change) reports have served as a scientific basis for global negotiations on the reduction of carbon emissions within the framework of the United Nations (UN), which is the world's most encompassing political framework for addressing problems of a planetary scope. Scientific assessment has provided a compelling rationale for lowering global carbon emissions, and the UN has agreed to do so since the signing of the United Nations Framework Convention on Climate Change in 1992, followed by 21 conferences of the parties, to date. ${ }^{2}$ Technological solutions are available, even if their application creates difficult policy choices and potentially high costs. However, technologically speaking, a gradual switch in energy systems to renewable energies is possible. Increases in energy efficiency are technologically feasible (eg, more efficient power plant technologies, using more 
energy efficient appliances, and improving insulation in buildings), and emission control technologies for several GHGs are available. However, despite all the global diplomatic efforts and the availability of technological solutions, global carbon emissions stemming from human production and consumption remain on the rise. ${ }^{3}$ The research puzzle for the social sciences is to explain why this discrepancy exists, why it is so persistent over time, and what opportunities can be identified to achieve a transformation toward a low-carbon society. In part, the slow response to climate change may be explained by the weak UN framework having been unable to generate a binding global policy regime. ${ }^{4}$ Further explanation may be found by looking at the most fundamental dynamics of capitalism, a form of economic production that is almost global in reach. ${ }^{5}$ The post-growth or de-growth debate takes up this capitalist perspective and discusses ways to depart from the inescapable growth dynamic inherent in the capitalist mode of production, which is responsible for everincreasing side effects and negative externalities. ${ }^{6}$ Another perspective analyzes the level of individual behaviors and actions as they account for a large portion of the global GHG output. If one can understand the factors driving individual consumption and mobility behavior, it would be possible or so one hopes - to identify options for a transformation that would work from the bottom up by reducing individual carbon footprints and accumulating the savings into a net global emission reduction. ${ }^{7}$

This review paper focuses on recent research findings on the preconditions for long-term individual carbon reduction gains. Conventional wisdom holds that the actions of individuals are impacted by how they perceive and understand the world, and how they identify problems and risks. The aim of this review article is to look at the links between the scientific risk assessment on anthropogenic climate change, public perceptions of climate change, and the possibilities of switching from high-carbon to low-carbon practices. To do so, the paper briefly summarizes the central aspects of the scientific assessment (The attribution of climate change to anthropogenic causes section) and then comments on the development of global climate negotiations (Climate policy development section). The main focus is a literature review on the public perception of climate change (The perception of climate change section), as well as on the persistence of highly carbon-intensive practices and the societal preconditions for widespread diffusion of low-carbon practices (The persistence of highly carbon-intensive practices section). This paper concludes with a brief reflection on the implications of the state of the research for the policy process.

\section{The attribution of climate change to anthropogenic causes}

The attribution of the observed increase in the global average surface temperature to human activities, has long been an important part of the scientific risk assessment on climate change. ${ }^{8}$ The attribution of climate change to anthropogenic sources is difficult because the global climate system has always been changing from natural causes and will continue to change so in the future. ${ }^{9}$ The question of attribution is relevant because it implies that within an extremely short period of time (relative to geological time scales), humans have discharged emissions into a global system at an order of magnitude that changes the basic parameters of this system. The attribution problem also directly affects the aspect of political responsibilities for mitigation. Therefore, the question is whether climate change can, at least in part, be attributed to anthropogenic sources. If this cannot be shown with a sufficient level of confidence, climate change may occur due to natural variations only. This finding would call for adaptation policies to protect against climate-related risks, but it would not be a basis on which to ground sweeping de-carbonization policies. The question of attribution can be traced back through all available assessment reports produced in the context of the IPCC, with the First Assessment Report published in 1990, the Second Assessment Report in 1995, the Third Assessment Report in 2001, Assessment Report 4 in 2007, and the latest, Assessment Report 5, in 2013 and 2014. ${ }^{10,11}$ The evidence that climate change can be attributed to human influence has again grown since Assessment Report 4. In this context, climate change does not only refer to changes in the average temperature of the earth's surface, but also to other critical dynamics such as ocean heat uptake and changing precipitation and storm patterns. ${ }^{11}$

In terms of the warming of the atmosphere and oceans, human influence has been detected for changes in global water cycles, reductions in snow and ice, rise in the global mean sea level, and changes in some climate extremes. ${ }^{12}$ Moreover, the emission of GHG is not the only relevant human activity in this context. Climate change has also been attributed to other anthropogenic processes. ${ }^{11}$ In its most recent Summary for Policy Makers of the Synthesis Report, the IPCC states that atmospheric concentrations of greenhouse gases were unprecendented in at least the last 800,000 years and continues:

Their effects, together with those of other anthropogenic drivers, have been detected throughout the climate system 
and are extremely likely to have been the dominant cause of the observed warming since the mid-20th century. ${ }^{13}$

Because the IPCC has provided the most comprehensive scientific risk assessment on climate change to date, this current paper is based on the relatively broad and solid consensus in the global scientific community that climate change can most likely be attributed to human causes. However, even in the face of scientific evidence, the fact that climate change is a complex process implies severe problems in understanding for even the educated lay person. One problem in understanding is due to the relationship between global and regional or local dynamics: even if the global mean temperature is an important indicator for global climate change, the way in which this global change manifests itself regionally or locally will differ substantially from any straightforward rise in mean temperature. Assessment Report 5 shows wide regional variation of key risks associated with anthropogenic climate change. The manifestations of global climate change will very likely differ across and within regions, and the associated risks may range from increased damage due to wildfires, to increased flood damage, heat-related human mortality, water restrictions, and vector- and waterborne diseases, among other things. ${ }^{14}$

The attribution of local climatic changes (rather than global trends) to anthropogenic sources is also more difficult:

This is because most of the local variability of local climate is averaged away in the global mean. ${ }^{15}$

The described complexities of anthropogenic climate change and the related scientific uncertainties ${ }^{16}$ create some difficulties in the perception and understanding of climate change by the public, in particular those uncertainties that relate to local manifestations and impacts of global climate change, and to the intricate relationship between climate change and other factors influencing parameters of the earth system which are relevant for human uses. ${ }^{17}$ Public perception of scientific uncertainties may lead to skepticism regarding the IPCC risk assessments or to a low readiness to adopt low-carbon practices. ${ }^{18,19}$ Before focusing on the development of public perception on climate change, I briefly summarize recent climate policy developments in the context of scientific evidence.

\section{Climate policy development}

Anthropogenic climate change is not only a scientific puzzle but also a governance object. ${ }^{20}$ Since the early 1990s, there have been serious attempts to develop a global approach to climate mitigation polices within the UN negotiation framework. In the early years, commentators suggested that a globally binding agreement to prevent dangerous levels of climate change might be built by following the positive example of the Montreal Protocol. The latter, for a number of different reasons, led to the phasing out of emissions from industrial sources harmful to the stratospheric ozone layer. ${ }^{21}$ However, it was soon realized that the preconditions for a climate agreement were much more complex than in the case of the Montreal Protocol, ${ }^{22}$ as fossil fuels provide the energetic basis of human development and well-being. Phasing out a few harmful substances for which technological substitutes exist or can be found in a short time is relatively easy. It is much more difficult to depart from a growth model with a global reach based on the unlimited use of fossil fuels, for which huge infrastructures have been built over the past 2 centuries. ${ }^{23}$ To understand the seemingly slow progress of international climate diplomacy, one has to acknowledge the messiness and conflict-ridden nature of anthropogenic climate change as a policy problem. Negotiations for a treaty to protect the ozone layer could be organized around a set of technical issues: how to substitute harmful substances, how to monitor the phasing out, and how to compensate for moderate economic losses connected to compliance with the protocol in some parts of the world. Negotiations for a treaty to prevent dangerous anthropogenic climate change has to address the much more complex transformation of the way the entire system of energy provision and consumption is set up, ie, the core of the world's model for economic growth and well-being. Difficult choices would have to be made by many governments, and this would require conflicting vested interests to be mediated and powerful resistance to be overcome, with a convincing low-carbon model of sustainable growth not yet in sight. The long-term transformation of energy systems will necessarily be a conflictual and inescapably political (rather than technological) process. ${ }^{24,25}$ The UN system has served as the negotiation framework for more than 2 decades but, so far failed to bring about collective action at the necessary level of strictness. One obvious problem is that the UN system does not have the executive power of a world government and unlike national governments, cannot issue and implement laws. Binding international agreements must be based on a consensus, and several alliances of countries and country groups have acted successfully as veto powers over time, slowing action considerably. Several times, negotiations have been in a stalemate situation, with too much political confrontation and too many vested interests that could not be overcome by consensus. ${ }^{26}$ From this difficult constellation, several trends have emerged. 
Carbon markets as a dominant solution: the creation of carbon markets appeared from the early 2000s onward as a promising alternative to other policy instruments. The European Union Emissions Trading Scheme was implemented as the first large-scale carbon market implemented in 2005. ${ }^{27}$ Many other carbon trading schemes followed in the years since then in all world regions except for Africa. Putting a price on carbon emissions now seems like a viable "technical" solution that takes out much of the political conflict and transfers it to the logics of the market, which would provide flexible, low-cost solutions to the low-carbon challenge. ${ }^{28}$ However, even though carbon markets look like beautiful and elegant solutions in economic theory, the realities of how they are set up and institutionalized reveal many types of systematic problems that can be seen as serious limitations to the potential of carbon markets to deliver long-term low-carbon developments. ${ }^{29}$ For example, the European Union Emissions Trading Scheme suffers from a persisting over-allocation of emission allowances which so far has hindered a massive impact on investment decisions toward low carbon technologies.

Multiplication of policy levels: another trend pertains to other levels of policy development, eg, at the level of local city administrations. At local governance levels, ${ }^{30}$ a growing number of worldwide initiatives have begun to explore the possibilities of city administrations to contribute to climate mitigation policies and promote the transition toward lowcarbon development pathways. The network International Council for Local Environment Initiatives and the so-called transition town movement are the most prominent examples. In a reflection about the potential of urban governance in achieving climate protection, Bulkeley and Betsill concluded in 2005 that the urban level is embedded in complex vertical linkages between state institutions and the emergence of new political spaces. ${ }^{31}$ As a consequence, urban governance can become effective only if it relates to multilevel governance arrangements, but not at an isolated policy level. In a more recent reassessment, the same authors discussed considerable changes within a few years only: a proliferation of interventions, projects, and initiatives at the municipal level, demonstrating a huge potential for emission reductions and concurrent benefits. However, the overall policy effects are still extremely difficult to assess. ${ }^{32}$

Search for alternative policy regimes: against this backdrop, many authors acknowledge that states or national governments are still the only actors that can generate the necessary legitimacy and can draw from the necessary legal and financial resources to develop visions and implement programs for the long-term transformation of entire energy systems. ${ }^{33}$ Based on this insight, new policy strategies have been suggested that build on national interests and differentiated domestic policy approaches as building blocks of a polycentric climate regime, as an addition to the consensusbased global UN climate regime. One example would be to establish bottom-up carbon pricing systems in individual countries which can create a number of co-benefits. ${ }^{34}$

The overall picture of climate policy development can be described as slow progress at the global regime level, contrasted by a proliferation of regional, national, and subnational policies and instruments to mitigate climate change, the effectiveness of which has been assessed with mixed results. ${ }^{35}$ In this situation, the questions arise of what is known about the development of low-carbon practices at the level of individual citizens or consumers and how can these developments be understood. Because the problem of public perception is seen by many to be a key factor influencing individual behavior and actions, the paper will now focus on the issue of changes in the public perception of climate change in the past decades.

\section{The perception of climate change}

Public perception of climate change has been discussed and measured since the 1980s. ${ }^{36,37}$ Early on, large portions of the lay public saw global warming as a problem and showed some concern, while acknowledging a low level of understanding of the basic causal relations leading to it. ${ }^{38}$ Studies over the years, regarding what people actually know about climate change have at times shown considerable progress, as in a recent local study in the US that demonstrated considerable improvement in knowledge about basic causal relations and a near disappearance of some of the early misconceptions on climate change. ${ }^{39}$ However, typical misperceptions can still be found, and studies have been conducted to improve information policies about climate change. ${ }^{19}$ In a recent comprehensive literature review on trends in public opinion over the past quarter century, Capstick et al distinguished four different phases. ${ }^{40}$

From the 1980s to the early 1990 s, public opinion polls worldwide showed an increasing basic awareness of climate change as a problem. However, there was limited knowledge about basic facts, and many respondents confused global warming with ozone depletion or local air pollution. Interestingly, at that time, many people believed that the climate was already changing. From the mid-1990s to around 2005, steady growth and deepening concern were shown by many studies, with shares between $50 \%$ and $70 \%$ of the respondents 
thinking that global warming caused a fair amount or even a great deal of worry in the US, and in other countries. Despite variations between and within countries, this was a phase of relatively broad public support for climate mitigation policies worldwide, when a popular consensus for action on climate change formed. In contrast, the period from around 2005 to 2010 showed increasing skepticism, especially within AngloSaxon countries, and a growing polarization of opinions in some countries such as in the US. ${ }^{41}$ The percentage of respondents who believed that climate change was a conspiracy theory rose, and in that period, the share of respondents who were skeptical about the human causation of climate change, its potential negative impacts, and the existence of a scientific consensus on climate change peaked at approximately $40 \%$ in the $\mathrm{UK}^{42}$ and the US. ${ }^{43}$ In contrast, this phase coincided with worldwide growth in media coverage on climate change, especially between the years 2006 and $2009 .{ }^{44}$ In the early 2010s, the decline of concern and the rise of skepticism in the US and Europe seemed to be coming to a halt. Recent studies have shown a stabilization of public concern for climate change, even though there is some volatility between the years and still huge variation between countries and world regions. ${ }^{40}$ Examples from other countries also show a lower overall percentage of public skepticism regarding climate change compared to Anglo-Saxon countries. ${ }^{45}$

What are the implications of these findings? Some commentators doubt that a deep understanding of the complex causes of climate change or even a deep concern for the risks associated with climate change impacts is a necessary precondition for climate mitigation policies. ${ }^{38,46}$ However, a huge group of climate skeptics with some political leverage are a serious barrier to further policy engagement. One question is what factors drive skepticism. ${ }^{42,43,45,47,48}$ Several drivers have been discussed in the literature. Economic explanations found some support, especially in connection with insecure labor market conditions during the recession before $2010 .{ }^{49}$ Others have looked at organized disinformation campaigns by corporate sponsored activism groups. ${ }^{50,51}$ However, by far the most consistent explanation can be found in underlying political orientations and broad environmental attitudes, ie, pre-existing values and world views. ${ }^{42,43,45,48}$

This finding suggests that the public perception of climate change should probably be conceptualized more in terms of beliefs and worldviews, than in terms of knowledge and information. The literature on framing deals closely with the questions of how these beliefs and worldviews are formed and how this connects to feelings of responsibility and the motivation to change behavior. ${ }^{52,53}$ Frame is used as a concept to analyze how the central organizing idea about the essence of an issue emerges. In the context of this paper, frames are used to show how the idea of what climate change is, and what problem it implies, develops in the public mind. ${ }^{54}$ The concept of frames usually includes distinct sets of diagnostics (identifying the problem), prognosis (finding problem solutions), and motivations (encouraging action). ${ }^{55}$ Frames can include scientific aspects, but often they emphasize the moral, economic, or yet other aspects of a problem. Usually we can observe several competing frames. Some become dominant over time and structure the way how most people perceive a given problem (in our case climate change). But different frames can become dominant in different contexts (eg, in different national contexts). Research on framing is used to show that not only do opinions and concerns about climate change vary across countries and regions but even the very concept by which people understand and try to make sense of climate change varies accordingly. A study about frames in Twitter communications from four English-speaking countries over 2 years has revealed large differences in the sense that US users are much more preoccupied with the question of whether global climate change is real or a lie than with questions about the causes, impacts, and solutions of climate change, as compared with UK, Canadian, and Australian users. However, again, these differences also vary strongly with general political orientations, especially among US users. ${ }^{56}$

Some have argued that frames can be used strategically to build support for climate mitigation policies. In particular, the ways in which uncertainties, costs, and normative guidelines are combined in a frame may affect the type and level of public support: eg, framing costs as a smaller increase in future income proved to be favorable, ${ }^{53}$ as did generally using positive frames rather than negative ones. ${ }^{52} \mathrm{~A}$ different study used a laboratory setting to measure the influence of global versus local frames and cost frames (the costs of dealing with climate impacts) versus benefit frames (including the potential benefits of climate change) on the level of concern over climate change, behavioral intentions, and support for local policy action. They found that benefit framing decreased perceptions of problem severity but did not decrease behavioral intentions to address climate change and that the local vulnerability frame generated much stronger levels of support for local policy action than a global frame. ${ }^{57}$

Applying a framing analysis to the ways in which climate change has been communicated by non governmental organizations, Della Porta and Parks show a substantive shift in recent years from the broad frame of "climate change" 
to the frame of "climate justice". ${ }^{55}$ The newer frame of climate justice makes room for broader public engagement for several reasons: the frame is much more appealing for groups in the global south, it allows frame bridging to other global justice movements, and it better reflects a common culture of shared ownership (eg, of the earth's atmosphere) than the more conventional frame of climate change, with the concept of charismatic leaders agreeing on global policy solutions. $^{58,59}$

Summarizing this section, it is important to accept that perceptions of climate change are deeply embedded in pre-existing concerns, beliefs, and worldviews and that the frames that are typically used in communications about climate change can influence the motivations and intentions to act or support for policy actions. Frames even define at which level of collective or individual action problem solutions can be found in the first place, with only some frames suggesting the need for global binding agreements and other frames implying a much stronger focus and reliance on individual behavioral change. ${ }^{20}$ This leads to the next section, in which the linkage between perceptions or beliefs about climate change and individual actions are addressed in a more systematic way.

\section{The persistence of highly carbon- intensive practices}

The most direct link between individual behavior and climate mitigation is consumption. What and how do people consume? How does this influence global GHG emissions? What are available alternatives? A broad conceptual study systematically analyzes the carbon footprint of five main consumption categories (food, shelter, travel, goods, and services) and identifies connected technological consumption options that would result in lower GHG emissions. ${ }^{60}$ The consumption of food offers three low GHG consumption options: increased vegetal foodstuffs, avoidance of vegetables transported by air or produced in heated greenhouses, and replacement of ruminant meat (eg, beef) by non ruminant meat (eg, pork or chicken). Shelter is also a basic need: apart from the energy-intensive construction of buildings, heating (and cooling in warmer countries) is the most GHG intensive activity. The GHG intensity of heating can be reduced mainly by better insulation, switching to renewable energy sources, improving energy efficiency, and retrofitting older buildings. Travel behaviors can switch to low-GHG options if vehicles are powered by renewable energies (especially trains and electric bikes). So far, there are no available lowGHG alternatives to conventional air travel, but high-speed trains can, at least in some cases, provide alternatives with reduced GHG emissions. The consumption of goods requires a differentiated analysis because the energy intensity of products varies enormously with the production and resource extraction processes. Using natural products from extensive farming, recycling materials, reusing materials, and extending the lifetime of materials are viable options for lowering the GHG consumption of goods. As for the consumption of services, the available option to lower the GHG intensity is to choose services that are labor intensive, rather than energy intensive. Further, a switch to renewable energies and changes in practices (less use) are available across all fields of consumption that require the use of electric power. ${ }^{60}$

However, in spite of many available technological options and low-carbon alternatives and a widespread willingness to mitigate climate change, carbon-intensive practices still prevail. Many systematic reasons for this can be found when analyzing the meanings of consumption and a whole range of barriers to change. Often it is the lack of a specific type of infrastructure (eg, electrical mobility, heating households, or the availability of low-carbon goods and services) that is the most persistent barrier to change. ${ }^{61,62}$ Moreover, consumption is a very complex social and cultural activity. ${ }^{63}$ The consumption of food, for example, is in most cases not just a mechanical response to a biophysical basic need, but embedded in a set of cultural meanings, ideas about one's identity, and the representation of one's self. ${ }^{64}$ One's choice of food is thus more about who a person is than about what this person wants to do about climate change. Many consumption practices have become increasingly moralized, ${ }^{65}$ but the linkages between moralization and action and between beliefs about climate change and the willingness to engage in climate mitigation on a personal level are not very straightforward. This is true both ways: climate-friendly attitudes do not necessary lead to climate-friendly behavior, and skepticism about climate change does not necessarily prevent proenvironmental behavior. As one recent study showed, even if people are skeptical about climate change and about the personal responsibility for switching to low-carbon lifestyles, they can still be very concerned about the unsustainable use of resources and act accordingly. ${ }^{66}$

The literature on low-carbon consumption patterns is divided into studies following a behavioral paradigm on the one hand and studies focusing on social contexts, the systemic features of action situations, and social practices on the other. One prominent strand of literature in the behavioral paradigm has been inspired by the work of Ajzen on planned behavior. ${ }^{67}$ Authors have tried to identify the role of individual beliefs, 
attitudes, and values as determinants or predictors of proenvironmental behavior. These works have been criticized for their lack of understanding of the crucial influence of the context in which behavior is situated, their linear model of behavior, and the oversimplified expectations about the possibilities to induce behavior changes. ${ }^{68,69}$ However, this approach has been the basis for many policy interventions to promote low-carbon behavior, as has been particularly well documented for UK policies. ${ }^{69,70}$ Alternative approaches suggest a broader and more holistic understanding of why people remain locked in non-sustainable carbon-intensive practices.

Kurz et al discussed two different conceptual ways to move beyond the obvious shortcomings of the linear behavioral paradigm: the psychological perspective on habits and the sociological theory of social practice. ${ }^{71}$ Both perspectives assume that planned behavior (or deliberative action as it is called by Kurz et al) is often not at the heart of what goes on in the social world. ${ }^{71}$ In their paper, the authors looked at various examples of consumption with huge potential to switch from high-carbon to low-carbon consumption patterns. They demonstrated convincingly that the understanding of these consumption patterns can be much improved if one departs from looking only at deliberative actions to adopting a perspective of habitual and routine aspects of daily life. The psychological approach to habits emphasizes that many action patterns can be explained as automatic responses to a particular and repeatedly experienced context. The closer the link between the context and the behavioral response becomes (through repetition), the more automatically activated the behavior will be and the less cognitive effort will be involved. By this mechanism, consumption patterns can become selfperpetuating in stable contexts. Political interventions trying to promote behavioral change will then remain ineffective if they rely on information, moralization, or other attempts to change attitudes.

Theories of social practice also depart from a focus on deliberative action by individuals. Instead, they treat social practices, such as cooking, heating, and driving, as analytical units in themselves. By practice, these authors conceptualize ensembles of meanings and symbols, competences and procedures, and materials and technologies that are bound together in regular and repeated performances by practitioners. The practice approach is particularly well equipped for explaining why highly carbon-intensive patterns of consumption are so persistent over time and why policy interventions frequently fail. ${ }^{71}$ To understand patterns of individual transportation, for example, one would have to look at how driving from one place to the next is actually performed in a routine and takenfor-granted way, how the practice of driving is interconnected with many other practices (working, enjoying leisure time, taking care of family members, etc), and how it is inseparably linked to both specific meanings of driving and the specific material aspects of it. ${ }^{71}$ The consumption of energy, which is so crucial for the question of low-carbon intensive consumption patterns, is not looked at as a form of consumption in its own right. Rather than just by looking at the patterns of turning on or off electric devices, the consumption of energy can only be understood insofar as it is connected to social practices such as heating or cooking. ${ }^{72}$ As an outcome of these different approaches to understanding consumption patterns, several important lessons can be learned:

- many situations leading to one or another act of consumption can be better understood as habitual and routinized situations than as deliberative (planned) actions.

- The context in which these patterns of consumption take place is of crucial importance and often remains undertheorized.

- More holistic approaches to consumption provide better explanations to why highly carbon-intensive practices are so persistent, in spite of or at least independent from improved knowledge about climate change, heightened awareness about the risks of climate change, and growing pro-environmental attitudes. They can show how practices are stabilized because they are ensembles of competences, material aspects, and symbolic meanings and are entwined with many other practices at the same time.

There have been attempts to use the holistic approach not just to criticize oversimplified policy interventions but also to develop the basis for more effective policy programs. ${ }^{70}$ However, it is obviously difficult to change whole sets of social practices, and attempts to do so are still in their infancy. In the meantime, it might be a worthwhile consideration to rely on providing political regulation and creating new infrastructures at the systemic level in parallel to looking at the role that individual consumers can play by adopting low-carbon practices.

\section{Prospects and challenges for low-carbon development}

This paper provides an overview of current research that might help to explain the weak links between the scientific evidence on anthropogenic climate change, the public perception of climate risks, and the persistence of highly carbon-intensive practices. The scientific consensus that 
has been brought about by the IPCC on the attribution of climate change to anthropogenic sources provides a strong rationale for global attempts to lower GHG emissions from human sources and to actively search for low-carbon development pathways. However, despite a global policy regime to achieve emission reductions having been in place for more than 2 decades, so far no path departure from a carbon-intensive growth pattern has been achieved. GHG emissions are still rising globally. This trend is all the more remarkable given the multiplication of policy levels at which climate change is addressed, the proliferation of policies to address climate change, and the widespread diffusion of concern for climate change and climate-related risks, as well as pro-environmental and climate-friendly attitudes. However, if we apply a holistic view for understanding patterns of consumption, the persistence of highly carbon-intensive practices becomes understandable. Despite the huge theoretical (technological) potential of lowering anthropogenic GHG emissions by individual consumers switching to low-carbon practices, the broader and more holistic approach provided by practice theories provides some skepticism as to how fast and how reliable this potential can be realized. Therefore, the need to deliver new types of infrastructure or laws and regulation that address the systemic levels of production and consumption remains. The literature review also suggests that one should not simply wait for binding commitments at the global policy level; rather, there should be more systematic exploration of tie-in strategies at other policy levels and evaluation of proactive attempts to switch national systems of energy provision and consumption that can be observed in a growing number of countries, in addition to municipalities on a local level around the globe.

\section{Acknowledgments}

The author would like to thank Jochem Marotzke and two anonymous reviewers for valuable comments. The review was written in the context of the Cluster of Excellence "Integrated Climate System Analysis and Prediction (CliSAP)", DFG EXC 177.

\section{Disclosure}

The author has no conflicts of interest in this work.

\section{References}

1. IPCC: https://www.ipcc.ch/organization/organization_history.shtml. Accessed January 6, 2016.

2. http://unfccc.int/essential_background/items/6031.php. Accessed January 6, 2016.
3. PBL Netherlands Environmental Assessment Agency, European Commission Joint Research center 2014. Trends in global $\mathrm{CO}_{2}$ Emissions. 2014 Report. The Hague; 2014: JRC93171. Available from: http://edgar. jrc.ec.europa.eu/news_docs/jrc-2014-trends-in-global-co2-emissions2014-report-93171.pdf. Accessed December 3, 2015.

4. Keohane RO, Victor DG. The regime complex for climate change. Perspectives on Politics. 2011;9(1):7-23.

5. Newell P. The elephant in the room: Capitalism and global environmental change. Global Environmental Change. 2011;21(1):4-6.

6. Victor PA. Growth, degrowth and climate change: A scenario analysis. Ecological Economics. 2012;84:206-212.

7. Owens S, Driffill L. How to change attitudes and behaviours in the context of energy. Energy Policy. 2008;36(12):4412-4418.

8. Hegerl GC, von Storch H, Hasselmann K, Santer BD, Cubasch U, Jones PD. Detecting greenhouse-gas-induced climate change with an optimal fingerprint method. Journal of Climate. 1996;(6)9: 2281-2306.

9. Bindoff NL, Stott PA, AchutaRao KM, et al. Detection and attribution of climate change: from global to regional. In: Stocker TF, Qin D, Plattner DK, et al, editors. Climate Change 2013: The Physical Science Basis. Contribution of Working Group I to the Fifth Assessment Report of the Intergovernmental Panel on Climate Change. Cambridge, United Kingdom and New York: Cambridge University Press; 2013:878.

10. IPCC, 2007: Climate Change 2007: Synthesis Report. Contribution of Working Groups I, II and III to the Fourth Assess-ment Report of the Intergovernmental Panel on Climate Change [Core Writing Team, Pachauri, R.K and Reisinger, A. (eds.)]. IPCC, Geneva, Switzerland.

11. IPCC. 2013: Summary for policymakers. In: Stocker TF, et al. editors. Climate Change 2013: The Physical Science Basis. Contribution of Working Group I to the Fifth Assessment Report of the Intergovernmental Panel on Climate Change. Cambridge, United Kingdom and New York: Cambridge University Press. 2013.

12. IPCC. 2013: Summary for policymakers. In: Stocker TF, et al. editors. Climate Change 2013: The Physical Science Basis. Contribution of Working Group I to the Fifth Assessment Report of the Intergovernmental Panel on Climate Change. Cambridge, United Kingdom and New York: Cambridge University Press. 2013;17.

13. IPCC [homepage on the Internet]. Climate Change 2014: Synthesis Report. Summary for Policymakers. IPCC; 2014:4. Available from: http://www.ipcc.ch/report/ar5/syr/. Accessed December 3, 2015.

14. IPCC [webpage on the Internet]. Climate Change 2014: Synthesis Report. Summary for Policymakers. IPCC; 2014:14. Available from: http://www.ipcc.ch/report/ar5/syr/. Accessed December 3, 2015.

15. Bindoff et al. Climate Change 2013: The Physical Science Basis. Contribution of Working Group I to the Fifth Assessment Report of the Intergovernmental Panel on Climate Change. Cambridge, United Kingdom and New York: Cambridge University Press; 2013:928.

16. IPCC [webpage on the Internet]. Climate Change 2014: Synthesis Report. Summary for Policymakers. IPCC; 2014:4. Available from: http://www.ipcc.ch/report/ar5/syr/. Accessed December 3, 2015.

17. Jaramillo F, Destouni G. Developing water change spectra and distinguishing change drivers worldwide. Geophysical Research Letters. 2014;41(23):8377-8386.

18. Ding D, Maibach EW, Zhao X, Roser-RenoufC, Leiserowitz A. Support for climate policy and societal action are linked to perceptions about scientific agreement. Nature Climate Change. 2011;1:462-466.

19. Moxnes E, Saysel AK. Misperceptions of global climate change: Information policies. Climatic Change. 2009;93(1):15-37.

20. Corry O, Jørgensen D. Beyond 'deniers' and 'believers': Towards a map of the politics of climate change. Global Environmental Change. 2015;32:165-174.

21. Benedick RE. Ozone diplomacy: new directions in safeguarding the planet. 2nd ed. Cambridge: Harvard University Press; 2009.

22. Sunstein CR. Of Montreal and Kyoto: A tale of two protocols. Harvard. Environmental Law Review. 2007;31(1). 
23. Unruh GC, Carrillo-Hermosilla J. Globalizing carbon lock-in. Energy Policy. 2006;34(10):1185-1197.

24. Meadowcroft J. What about the politics? Sustainable development, transition management, and long term energy transitions. Policy Sciences. 2009;42(4):323-340.

25. Lövbrandt E, Beck S, Chilvers J, et al. Who speaks for the future of Earth? How critical social science can extend the conversation on the Anthropocene. Global Environmental Change. 2015;32:211-218.

26. Bodansky D. The Copenhagen Climate Change Conference: A postmortem. The American Journal of International Law. 2010;104(2): 230-240.

27. Ellerman AD, Convery FJ, de Perthuis C. Pricing Carbon: The European Union Emissions Trading Scheme. Cambridge: Cambridge University Press; 2010.

28. Bernstein ST, Betsill M, Hoffmann M, Paterson M. A tale of two copenhagens: carbon markets and climate governance. Millenium - Journal of International Studies. 2010;39(1):161-173.

29. Stephan B, Paterson M, editors. Environmental Politics. Taylor and Francis: 2012;21(4).

30. Pohlmann, A. local climate change governance. In: Engels A, editor. Global transformations towards a low carbon society. Hamburg, University of Hamburg, KlimaCampus; 2011:5.

31. Bulkeley H, Betsill M. Rethinking sustainable cities: Multilevel governance and the 'urban' politics of climate change. Environmental Politics. 2005; 14(1):42-63.

32. Bulkeley H, Betsill M. Revisiting the urban politics of climate change. Environmental Politics. 2013;22(1):136-154.

33. Jordan A, Huitema D. Policy innovation in a changing climate: Sources, patterns and effects. Global Environmental Change. 2014;29: 387-394.

34. Edenhofer O, Jakob M, Creutzig F, et al. Closing the emission price gap. Global Environmental Change. 2015;31:132-143.

35. Auld G, Mallett A, Burlica B, Nolan-Poupart F, Slater R. Evaluating the effects of policy innovations: Lessons from a systematic review of policies promoting low-carbon technology. Global Environmental Change. 2014;29:444-458.

36. John C, Pierce JC, Lovrich NP Jr. Knowledge and politics: The distribution and consequences of policy-relevant information among citizens, activists, legislators, and experts. Science Communication. 1982;3(4):521-554.

37. Dunlap RE, Scarce R. The polls and poll trends: Environmental problems and protection. Public Opinion Quarterly. 1991;55:651-672.

38. Dunlap RE. Lay perceptions of global risk. International Sociology. 1998;13(4):473-498.

39. Reynolds TW, Bostrom A, Read D, Morgan MG. Now what do people know about global climate change? Survey studies of educated lay people. Risk Analysis. 2010;30(10):1520-1538.

40. Capstick S, Whitmarsh L, Poortinga W, Pidgeon N, Upham P. International trends in public perceptions of climate change over the past quarter century. WIREs Climate Change. 2015;6(1):35-61.

41. Hoffman AJ. The growing climate divide. Nature Climate Change. 2011;1:195-196.

42. Poortinga W, Spence A, Whitmarsh L, Capstick S, Pidgeon NF. Uncertain climate: An investigation into public skepticism about anthropogenic climate change. Global Environmental Change. 2011;21:1015-1024.

43. McCright AM, Dunlap RE. Cool dudes: The denial of climate change among conservative white males in the United States. Global Environmental Change. 2011;21:1163-1172.

44. Schmidt A, Ivanova A, Schäfer MS. Media attention for climate change around the world: A comparative analysis of newspaper coverage in 27 countries. Global Environmental Change. 2013;23(5):1233-1248.

45. Engels A, Hüther O, Schäfer M, Held H. Public climate-change skepticism, energy preferences and political participation. Global Environmental Change. 2013;23(5):1018-1027.

46. Rhodes E, Axsen J, Jaccard M. Does effective climate policy require well-informed citizen support? Global Environmental Change. 2014;29: 92-104.
47. Smith N, Leiserowitz A. The rise of global warming skepticism: Exploring affective image associations in the United States over time. Risk Analysis. 2012;32(6):1021-1032.

48. Whitmarsh L. Scepticism and uncertainty about climate change: Dimensions, determinants and change over time. Global Environmental Change. 2011;21(2):690-700.

49. Scruggs L, Benegal S. Declining public concern about climate change: Can we blame the great recession? Global Environmental Change. 2012;22(2):505-515.

50. Kolmes SA. A disinformation campaign. Environment. 2011;53(4): 33-37.

51. Oreskes N, Conway EM. Merchants of Doubt. New York: Bloomsbury Press; 2010.

52. Morton TA, Rabinovich A, Marshall D, Bretschneider P. The future that may (or may not) come: How framing changes responses to uncertainty in climate change communications. Global Environmental Change. 2011;21(1):103-109.

53. Hurlstone MJ, Lewandowsky S, Newell BR, Sewell B. The effect of framing and normative messages in building support for climate policies. PLoS One. 2014;9(12):e114335.

54. Gamson WA, Modigliani A. The changing culture of affirmative action. Research in Political Sociology. 1987;3:137-177.

55. Della Porta D, Parks L. Framing process in the climate movement. In: Dietz M, Garretts H. Routledge Handbook of Climate Change Movement. London: Routledge; 2013:19-30.

56. Jang SM, Sol Hart P. Polarized frames on "climate change" and "global warming" across countries and states: Evidence from Twitter big data. Global Environmental Change. 2015;32:11-17.

57. Wiest SL, Raymond L, Clawson RA. Framing, partisan predispositions, and public opinion on climate change. Global Environmental Change. 2015;31:187-198.

58. Bulkeley H, Edwards GA, Fuller S. Contesting climate justice in the city: Examining politics and practice in urban climate change experiments. Global Environmental Change. 2014;25:31-40.

59. Benford R, Snow A. Framing processes and social movements: An overview and assessment. Annual Review of Sociology. 2000;26:611-639.

60. Girod B, Van Vuuren DP, Hertwich EG. Climate policy through changing consumption choices: Options and obstacles for reducing greenhouse gas emissions. Global Environmental Change. 2014;25:5-15.

61. Bulkeley H, Castán Broto V, Maassen A. Low-carbon transitions and the reconfiguration of urban infrastructure. Urban Studies. 2014;51(7):1471-1486.

62. Loorbach D, Frantzeskaki N, Thissen W. Introduction to the special section: Infrastructures and transitions. Technological Forecasting and Social Change. 2010;77(8):1195-1202.

63. McCracken G. Culture and Consumption. Bloomington: Indiana University Press; 1990.

64. Grauel J. Being authentic or being responsible? Food consumption, morality and the presentation of self. Journal of Consumer Culture. 2014:1-18.

65. Butler C. Morality and climate change: Is leaving your TV on standby a risky behaviour? Environmental Values. 2010;19(2):169-192.

66. Fischer A, Peters V, Neebe M, et al. Climate change? No, wise resource use is the issue: Social representations of energy, climate Change and the future. Environmental Policy and Governance. 2012; 22(3):161-176.

67. Ajzen I. The theory of planned behavior. Organizational Behavior and Human Decision Processes. 1991;50(2):179-211.

68. Shove E. Gaps, barriers and conceptual chasms: Theories of technology transfer and energy in buildings. Energy Policy. 1998;26(5): $1105-1112$.

69. Shove E. Beyond the ABC: Climate change policy and theories of social change. Environment and Planning A. 2010;42(6):1273-1285.

70. Hargreaves T. Practiceing behaviour change: Applying social practice theory to pro-environmental behaviour change. Journal of Consumer Culture. 2011;11(1):79-99. 
71. Kurz T, Gardner B, Verplanken B, Abraham C. Habitual behaviors or patterns of practice? Explaining and changing repetitive climate-relevant actions. WIREs Climate Change. 2015;6(1):113-128.
72. Shove E, Walker G. What is energy for? Social practice and energy demand. Theory, Culture and Society. 2014;31(5):41-58.

\section{Publish your work in this journal}

Energy and Emission Control Technologies is an international, peer-reviewed, open access journal publishing original research, reviews, editorials and commentaries on developing technologies to optimize energy production and control of emissions. The manuscript management system is completely online and includes a very quick and fair peer-review system, which is all easy to use. Visit http://www.dovepress.com/testimonials.php to read real quotes from published authors.

Submit your manuscript here: http://www.dovepress.com/energy-and-emission-control-technologies-journal 